\title{
Clinical Utility of Virtual Reality in Pain Management: A Comprehensive Research Review from 2009 to 2016
}

\author{
Maria Matsangidou ${ }^{1}$ \\ University of Kent \\ Kent, UK \\ M.Matsangidou@kent.ac.uk
}

\author{
Chee Siang Ang \\ University of Kent \\ Kent, UK \\ C.S.Ang@kent.ac.uk
}

\author{
Mohamed Sakel \\ East Kent Hospitals University \\ NHS Foundation Trust \\ Kent, UK \\ msakel@nhs.net
}

\begin{abstract}
Virtual Reality is a technology that allows users to experience a computer-simulated reality with visual, auditory, tactile and olfactory interactions. In the past decades, there have been considerable interests in using Virtual Reality for clinical purposes, including pain management. This article provides a systematic review of research on Virtual Reality and pain management, with an aim to understand the feasibilities of current Virtual Reality technologies and content design approaches in real world clinical use. More specifically, this article focused on current consumer-facing Virtual Reality technologies. An exhaustive search identified 29 relevant studies from 2009 to 2016. Overall, studies indicate that Virtual Reality is an effective technology in clinical settings, which can ameliorate patients' pain. However, overall results are inconclusive. Further research need to be conducted in order to articulate clearly under what circumstances Virtual Reality is an efficient tool and what attributes / characteristics of Virtual Reality are crucial on pain management.
\end{abstract}

Keywords: Pain; Pain Management; Virtual Reality; Head Mounted Display; Immersive Devises.

Key Points:

- Head-mounted VR (HMVR) can be an effective tool in clinical settings to ameliorate patients' pain.

\footnotetext{
${ }^{1}$ Corresponding Author
} 
- Because of technological advances in consumer electronics, it is feasible to use low cost HMVR in clinical settings.

- Design strategiqes for developing and delivering VR depend on the the type of pain and demographics.

- VR pain management works by distracting patients from their pain or giving them altered visual feedback. 


\section{Introduction}

Pain is a multidimensional and complex phenomenon, which refers to negative feelings. It can be defined as a reaction that is caused through a combination of threatening information that provides a reasonable sense of self-danger to the brain (Arntz and Claassens, 2004; Merskey and Bogduk, 1994; Moseley, 2003; Price, 1999). Pain can be caused by injury, illness or through any invasive medical process.

The significance of pain as human experience can be highlighted from the universality of this phenomenon and by means of high percentages of patients in pain. One out of four U.S. adults had suffered from a continuous pain, which last at least a year or even more (Hyattsville and National Centre for Health Statistics, 2007).

A variety of pharmacological analgesics and psychological methods have been used as medical treatments of pain. Research, for decades to present, has suggested that Virtual Reality (VR) technology may provide an alternative solution to pain management (Li, Montaño, Chen and Gold, 2011; Matsangidou, Ang, Mauger, Otkhmezuri, and Tabbaa, 2017). Pain management practices, are essential for patients' recovery, and usually put in charge nursing staff in both generalist and specialist context. Hence, they need to be aware of the innovative pain relief tools that are in the horizon and should be capable of counselling patients of any enquiries of future new treatment modalities.

Indeed, a range of studies have explored clinical uses of VR, including pain management, physical rehabilitation and psychotherapy (Morris, Louw and Grimmer-Somers, 2009; Riva, 2005; Rothbaum, Hodges and Kooper, 1997).

VR is a technology that allows users to transport themselves into a computer-simulated 3-Dimentional environment. This system provides the user with an overall illusion of different senses (often visual and auditory, and sometimes tactile and/or olfactory) and as a result creates a sense of immersion (Li, Montaño, Chen and Gold, 2011). It has been argued that VR as a technique could be applied in the clinical environment to manage pain. For instance, VR allows the patient to concentrate on the virtual experience, thus distracting him/herself form perceiving nociceptive signals, and pain (Hoffman, Seibel, Richards, Furness, Patterson and Sharar, 2006). 
Although, VR seems to be an effective tool on pain management, it has been found that it requires a significant amount of time commitment, provided from nursing staff for cleaning the equipment and for technical support (Markus, et al., 2009). This review investigates the effectiveness of low-cost consumer solutions. We believe that moving to low-cost and accessible solutions will decrease the need of technical and cleaning support. Patients will be able to have their own Head Mounted Display (HMD), which could lead to a personalized solution, reducing the cost and time of equipment maintenance.

There have been some past review papers on VR and pain management. We believe our review is timely, and it contributes to new insights to this area in the following ways: i) Our review focuses on technological aspects of VR and how they are applicable in real world clinical settings based. In particular, we are interested in how current consumer facing low cost VR can be used clinically. ii) We reviewed the general bibliography of VR on pain management. Our review aims to provide results on different types of pain, design strategies and population. iii) Finally, our review focused exclusively on immersive VR and Head Mounted Display (HMD) solutions, as opposed to past reviews which adopted a broader definition of VR (see section below). Therefore, our review presents a focused definition of immersive VR on pain management process.

\subsection{Types of VR}

There is a need to distinguish between several kinds of VR technologies. Current literature in the clinical use of VR often treats any form of computer-generated virtual world as VR. In this review, we will focus on immersive VR systems, meaning that the Virtual Environment (VE) is projected through some kind of Head Mounted Display (HMD) device, instead of VE displayed on a computer screen. We believe that it is important to distinguish between these different VR technologies as the level of immersion may affect the users and as a consequence the patients' experience. In addition, interactive modalities may also affect user experience, and hence clinical outcomes. For instance, VR systems based on keyboard and mouse may hamper the sense of immersion, compared to gesture-based systems where users interact with the VR more naturally with their hand and head movements. 
Based on Ma and Zheng (2011), there are three types of immersive VR systems. A non-immersive VR system is a desktop computer based 3D graphical system which allows the user to navigate the VE through keyboard, mouse and a small computer screen. A semi-immersive system is an improved system; where graphical display is projected on a large screen, and there may be some forms of gesture recognition system for natural interactions. Finally, the third type of VR is fully immersive head mounted system where users' vision is fully enveloped, creating a sense of full immersion.

In the last five years, low cost consumers-facing immersive VR systems have been developed and released (Table 1). These new affordable immersive VR technologies could provide us with a feasible solution which could be implemented in real clinical settings.

\begin{tabular}{llll}
\hline VR technology & Cost & Company & Website \\
\hline Google Cardboard & $\$ 14.95-\$ 120$ & Google, US & www.google.com/get/cardboard/ \\
\hline Gear VR & $\$ 99$ & Samsung, US & www.oculus.com/en-us/gear-vr/ \\
\hline i-glasses 920HR & $\$ 299$ & $\begin{array}{l}\text { i-O } \\
\text { Systems, CA }\end{array}$ & Display \\
\hline Sony PlayStation & $\$ 399$ & Sony, Australia & $\begin{array}{l}\text { www.playssesstore.com/i-3d.html } \\
\text { au/explore/playstation-vr/ }\end{array}$ \\
\hline Vuzix Wrap 1200VR & $\$ 500$ & Vuzix, NY & https://www.vuzix.com/ \\
\hline Oculus Rift & $\$ 599$ & Oculus, US & www.oculus.com/en-us/rift/ \\
\hline HTC Vive & $\$ 799$ & HTC, US & www.htcvive.com \\
\hline eMagin z800 3DVisor & $\$ 900$ & eMagin, NY & http://www.emagin.com/ \\
\hline
\end{tabular}

Table 1: VR technologies and cost

This current study reviewed research in the past 8 years (2009-2016) on pain management using immersive VR technologies. We systematically reviewed evidence from empirical / experimental studies of several types of pain in humans, addressing the following questions:

1) How effective is VR on pain management?

2) What are the VR HMD technologies used, and can current consumer facing technologies be used to allow for real world implementation for clinical use?

3) What are the VR content creation method, and how feasible it is for real world deployment?

4) What are the current limitations of VR technologies?

5) What are the future directions of VR technologies? 


\section{Method}

The review was conducted based on Bargas-Avila and Hornbæk (2011) and Cochrane methodology (Higgins and Green, 2008; Khan, Ter Riet, Glanville, Sowden and Kleijnen, 2001), consisted of 5 phases:

\subsection{Procedure}

\subsubsection{Phase 1: Potentially relevant publications identified}

Electronic Libraries: We searched six electronic libraries, which cover a balanced range of disciplines, including computer science/engineering, medical research and multidisciplinary sources. The libraries which included in the review were:

1. ACM Digital Library (ACM)

2. Google Scholar

3. IEEE Xplore (IEEE)

4. MEDLINE

5. Sage

6. ScienceDirect (SD)

We restricted the search to a timeframe of eight years (2009 to 2016), since we are aiming in recent technologies. Consumer-facing VR technologies have advanced quite significantly in the past five years.

Search terms: We used the exact two queries to all the libraries, since we are aiming to cover VR pain management through immersive VR technology. As a result we excluded from our analysis non-immersive and semi-immersive computer based technologies.

— Virtual Reality AND Pain

— Head Mounted Display AND Pain

Search procedure: The search term used to search the publication's title, abstract and / or keywords.

Search results: The total search that returned in phase 1 can be seen in Table 2 . 


\begin{tabular}{|c|c|c|c|c|c|c|}
\hline & ACM & Google Scholar & IEEE & MEDLINE & Sage & SD \\
\hline Virtual Reality AND Pain & 13 & 148 & 19 & 0 & 13 & 32 \\
\hline $\begin{array}{l}\text { Head Mounted Display } \\
\text { AND Pain }\end{array}$ & 4 & 33 & 2 & 0 & 1 & 3 \\
\hline Total Findings & 268 & & & & & \\
\hline
\end{tabular}

Table2: Findings per library and in Total

\subsubsection{Phase 2: Publications retrieved for detailed evaluation}

First exclusion: All search results from phase1 imported into the software "Paperpile". Then, we exclude manually possible entries with wrong years. We removed three wrong year entries. This narrowed down our findings to 265 papers.

Second exclusion: Duplicate publications between each library (e.g., different libraries produce the same result) and within each library (e.g., different terms produce the same result into the same library) were removed.

We removed 15 duplicate publications between each library. As a result we end up with 250 different papers. Then we searched for duplicates within each library. The duplicate articles that were provides by different terms were 41 . The total outcome of this phase, were 209 different papers.

Third exclusion: We narrowed the entries down to the original full papers that are written in English. We excluded papers that we did not have access to the full length, and papers that are not original full paper such as workshops, posters, speeches, reviews, magazine articles and generally grey literature without formal peer-review. As a result we excluded 107 papers. The 102 remaining papers were: 79 Journal Articles, 21 Conference papers, 2 book chapters.

\subsubsection{Phase 3: Publications to be included in the analysis}

Final exclusion: Since the focus on this review is on consumer VR we excluded studies which used bulky experimental VR equipment not suitable for clinical use (e.g., CAVE). We also excluded studies which did not use HMD and immersive technology. Since consumer solutions which has released by companies (Table 1) are using HMD and immersive technologies, we believe that similar studies to these technologies will add knowledge in the field and provide clinical environments and patients with portable, accessible and 
usable technologies in the future. Based on these criteria, in this phase we excluded any irrelevant paper that appeared in the first phase and were not excluded through the second phase filtering. These papers may appear in our findings, because they contain relevant words to the one that we searched but did not match to the specific technology content.

Based on these restrictions, we removed 73 irrelevant publications. As a result, we ended up with 29 relevant papers (27 Journal Articles and, 2 Conference papers) (Flowchart 1).

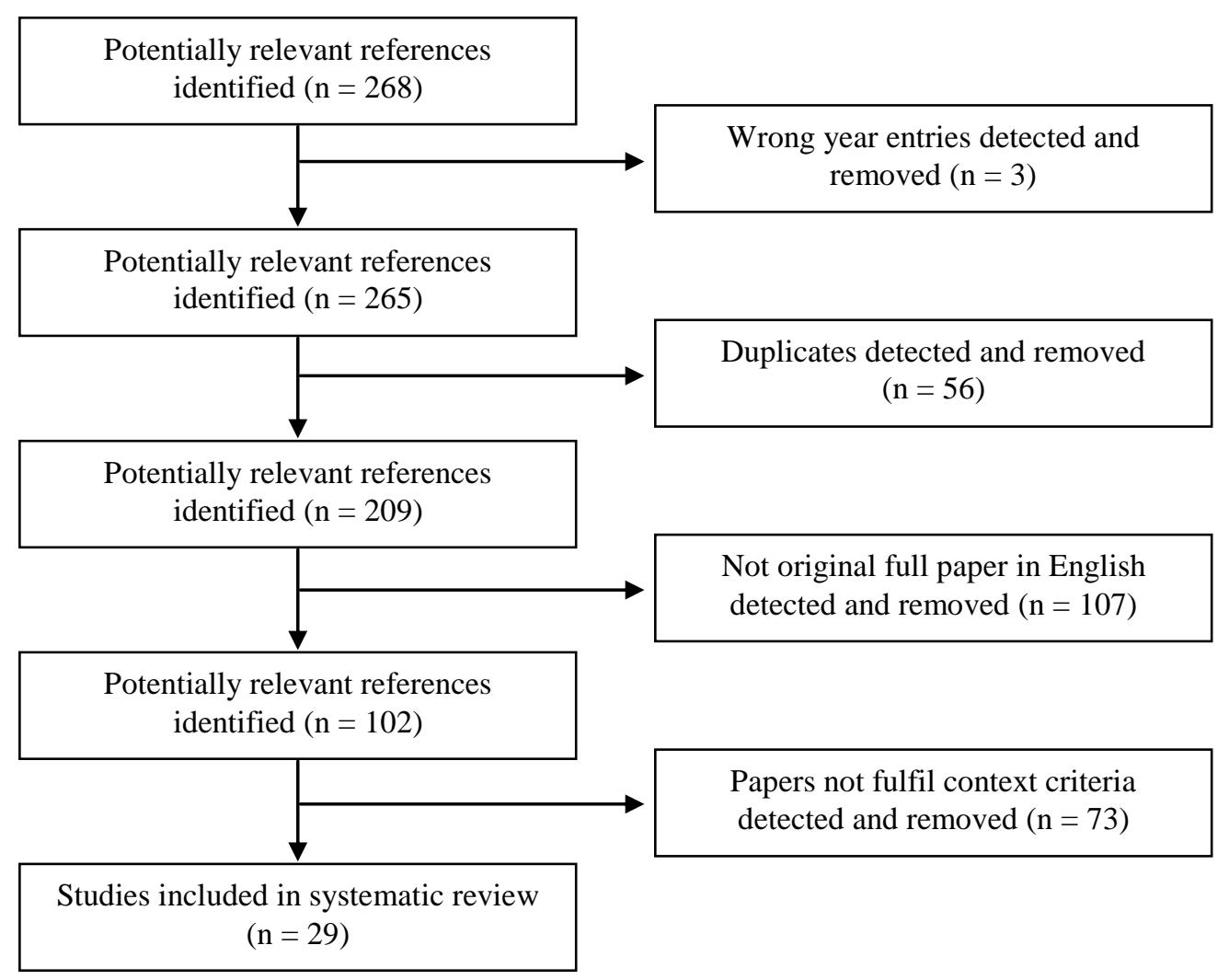

Flowchart 1: Paper's identification and selection

In the end of this phase, all corresponding PDFs downloaded for the analysis to be conducted.

\subsubsection{Phase 4: Data Gathering}

At this phase we extracted all the relevant information from the papers for the analysis to be conducted. In an excel file we extracted information from each study: the type of pain, the VE, the HMD and, the Interactivity devices it was used, the sample size of the population studied, the methodology, the 
instruments and the key findings. More over we labelled each study, based on the result as positive, negative or neutral.

\subsubsection{Phase 5: Data Analysis}

The data, collected in phase 4 , analyzed through descriptive statistics. Then we reviewed the literature to support, and enhance the additional knowledge that this paper provides. Thematic analysis was used as extra methodology in order to categorize our findings based on the themes. The themes we used included the types of HMD, the type of VE content, the Interactivity devices and the design strategies. Intercoder reliability was carried out between the researcher and the research assistant. Cohen's Kappa formula used to calculate the similarity between researcher and research assistant. The similarity was 0.89 .

\section{Results}

All the studies examined pain management on procedural pain. However, the types of pain differ considerably. More than half of the papers (15/29) focused on burn care. Those studies looked into burn injured patients and/or healthy population (using heat or cold stimuli to trigger pain similar to pain caused by burn injury). Seven papers focused on chronic pain in different parts of the body (specifically on neck, back and phantom limb pain). Chronic pain treatments in specific body parts differ based on the kind of pain. More explicitly, papers on chronic neck pain treatment focused on neck movements, whereas chronic back pain focused on back movements.

Only two studies looked into dental pain and five papers investigated other kind of pain, as shown in table 3. These studies include arm hemiplegic stroke pain, cancer - chemotherapy pain, wheelchair patient's pain and cystoscopy pain. Majority studies (52\%) focused on pain due to burn care (and thermal stimuliinduced pain).

\begin{tabular}{lll}
\hline Pain Type & Studies & Percentages $(\%)$ \\
\hline Burn Care - Thermal Stimuli & 15 & $52 \%$ \\
\hline Chronic Pain & 7 & $24 \%$ \\
\hline Dental Pain & 2 & $7 \%$ \\
\hline Other & 5 & $17 \%$ \\
\hline
\end{tabular}


Total

Table 3: Paper Content Descriptive Statistics

\subsection{Effectiveness of VR on pain management}

As can be seen in table 4, most of the studies (20/29) were controlled studies, where participants were allocated in two groups the VR and the Non-VR group (normally non-computerised intervention). Most (60\%) of the controlled experiments seem to have a positive effect on pain management in contrast to routine interventions. To illustrate it a bit more VR interventions seem to eliminate the procedural pain more than Non-VR. However, in some cases there were not differences in the two groups (40\%). Most of these results $(62.5 \%)$ involved real patients with pain problems (as opposed to healthy participants exposed to painful stimuli). Therefore, one key area of further investigation is to involve more real patients with pain problems, rather that healthy population exposed to painful stimuli.

Only one controlled study (Bahat, Takasaki, Chen, Bet-Or and Treleaven, 2015) investigated the relationship between VR procedural treatment and chronic pain in a long-term period. The findings revealed that even though VR treatment was more effective than Non-VR, the VR effect did not last in five weeks follow up evaluation. Therefore, one key area of further investigation needs to explore whether VR could provide a sustainable benefit in pain management.

Whilst most controlled studies showed positive outcomes, all the case studies (5/29) revealed positive results. These studies dealt with patients with a specific type of pain (e.g., burn, phantom limb, arm hemiplegic stroke and dental pain). Consequently, the case studies VE were focused on the specific characteristics of the type of pain, resulting in eliminating the procedural pain outcomes.

Overall, VR seems to show some potential on pain management. However, as it has been stated above specific characteristics on pain treatment and impermanent outcomes may affect the efficiency of VR on pain treatment.

\begin{tabular}{llll}
\hline Study & Type of Study & Virtual Environment & Outcomes \\
\hline Burn Care & & & \\
\hline Carrougher et al. (2009) & Controlled Study & $\begin{array}{l}\text { Icy 3D canyon surrounded by a } \\
\text { river, a waterfall and snowflakes }\end{array}$ & Positive \\
\hline Czub and Piskorz (2012) & Controlled Study & Prince of Persia and Split Second & Negative \\
\hline
\end{tabular}




\begin{tabular}{|c|c|c|c|}
\hline Czub and Piskorz (2014) & $\begin{array}{l}\text { Non-Controlled } \\
\text { Study }\end{array}$ & $\begin{array}{l}\text { Hit White and avoid Red Spheres } \\
\text { Game }\end{array}$ & Neutral \\
\hline $\begin{array}{l}\text { Dahlquist, Weiss, Clendaniel, Law, } \\
\text { Ackerman and McKenna (2009) }\end{array}$ & Controlled Study & Free Dive & Negative \\
\hline Dahlquist et al. (2010) & Controlled Study & Ice Age 2: The Meltdown & Negative \\
\hline $\begin{array}{l}\text { Dahlquist, Herbert, Weiss and Jimeno } \\
\text { (2010) }\end{array}$ & Controlled Study & Need for Speed Underground $2^{\mathrm{TM}}$ & Positive \\
\hline Hoffman, et al. (2014) & Case Study & SnowWorld & Positive \\
\hline $\begin{array}{l}\text { Kipping, Rodger, Miller and Kimble } \\
\text { (2012) }\end{array}$ & Controlled Study & $\begin{array}{l}\text { Chicken Little }^{\mathrm{TM}} \\
\text { Need for Speed }^{\mathrm{TM}}\end{array}$ & Positive \\
\hline Maani, et al. (2011) & Controlled Study & SnowWorld & Positive \\
\hline Markus, et al. (2009) & $\begin{array}{l}\text { Non-Controlled } \\
\text { Study }\end{array}$ & SnowWorld & Neutral \\
\hline Morris, Louw and Crous (2010) & Controlled Study & VR Game & Negative \\
\hline Rutter, Dahlquist and Weiss (2009) & Controlled Study & Catch Dory & Positive \\
\hline Schmitt, et al. (2011) & Controlled Study & SnowWorld & Positive \\
\hline Sil, et al. (2014) & Controlled Study & Sand Oasis & Positive \\
\hline $\begin{array}{l}\text { Wender, Hoffman, Hunner, Seibel, } \\
\text { Patterson and Sharar (2009) }\end{array}$ & Controlled Study & SnowWorld & Positive \\
\hline \multicolumn{4}{|l|}{ Chronic Pain } \\
\hline $\begin{array}{l}\text { Bahat, Takasaki, Chen, Bet-Or and } \\
\text { Treleaven (2015) }\end{array}$ & Controlled Study & Pilot flying an airplane & $\begin{array}{l}\text { Positive: } \\
\text { Not lasting }\end{array}$ \\
\hline Bolte, de Lussanet and Lappe (2014) & Controlled Study & Basketball arena & Positive \\
\hline Chen, Ponto, Sesto and Radwin (2014) & $\begin{array}{l}\text { Non-Controlled } \\
\text { Study }\end{array}$ & $\begin{array}{l}\text { To align a butterfly image with a } \\
\text { net image }\end{array}$ & Positive \\
\hline $\begin{array}{l}\text { Harvie, Broecker, Smith, Meulders, } \\
\text { Madden and Moseley (2015) }\end{array}$ & Controlled Study & $\begin{array}{l}4 \text { outdoor video } \\
2 \text { indoor video }\end{array}$ & Positive \\
\hline Sano, et al. (2015) & Case Study & Reaching task & Positive \\
\hline Wake, et al. (2015) & Case Study & Reaching task & Positive \\
\hline $\begin{array}{l}\text { Wiederhold, Gao, Sulea and } \\
\text { Wiederhold (2014) }\end{array}$ & Not specified & Relaxing video of natural areas & Positive \\
\hline \multicolumn{4}{|l|}{ Dental Pain } \\
\hline $\begin{array}{l}\text { Aminabadi, Erfanparast, Sohrabi, } \\
\text { Oskouei and Naghili (2011) }\end{array}$ & Controlled Study & Tom and Jerry Episode & Positive \\
\hline $\begin{array}{l}\text { Wiederhold, Gao and Wiederhold } \\
\text { (2014) }\end{array}$ & Case Study & Relaxing video of natural areas & Positive \\
\hline \multicolumn{4}{|l|}{ Other Types of Pain } \\
\hline $\begin{array}{l}\text { Crosbie, Lennon, McGoldrick, McNeill } \\
\text { and McDonough (2012) }\end{array}$ & Controlled Study & Reaching task & Negative \\
\hline $\begin{array}{l}\text { Gordon, Merchant, Zanbaka, Hodges } \\
\text { and Goolkasian (2011) }\end{array}$ & Controlled Study & Ringo & Negative \\
\hline Schneider, Kisby and Flint (2011) & Controlled Study & $\begin{array}{l}\text { Multiple VR scenarios, Patient } \\
\text { choose the scenario }\end{array}$ & Positive \\
\hline $\begin{array}{l}\text { Spyridonis, Gronli, Hansen and Ghinea } \\
(2012)\end{array}$ & Case Study & $\begin{array}{l}\text { VR model with body parts } \\
\text { interaction }\end{array}$ & Positive \\
\hline $\begin{array}{l}\text { Walker, Kallingal, Musser, Folen, Stetz, } \\
\text { and Clark (2014) }\end{array}$ & Controlled Study & SnowWorld & Negative \\
\hline
\end{tabular}

Table 4: VR Papers and VE (Positive $=$ VR eliminates significantly the procedural pain in contrast to Non$V R)$

\subsection{VR HMD technologies}


From the papers reviewed, we identified a range of VR HMD used in the studies. Some of them are considered low cost consumer solutions (lower than 1,000 USD), whilst others are high-end technologies often used only in the lab for scientific studies.

Low-cost solutions include VR Goggles, i-glasses 920HR, Vuzix Wrap 1200V, Oculus Rift and eMagin z800 3DVisor. The total cost of the HMD was between 14.95USD - 900USD. High-cost solutions include Kaiser SR-80, Nvis nVisor MH60, ProView VO35, 5DT: 800-26 and VFX3D and total cost range from 1,800 USD - 35,000USD.

Overall, most of the papers we reviewed used a low cost immersive VR solutions (14/29) (Aminabadi, Erfanparast, Sohrabi, Oskouei and Naghili, 2011; Bahat, Takasaki, Chen, Bet-Or and Treleaven, 2015; Chen, Ponto, Sesto and Radwin, 2014; Czub and Piskorz, 2012; 2014; Harvie, Broecker, Smith, Meulders, Madden and Moseley, 2015; Hoffman, et al., 2014; Kipping, Rodger, Miller and Kimble, 2012; Maani, et al., 2011; Morris, Louw and Crous, 2010; Sano, et al., 2015; Schneider, Kisby and Flin, 2011; Spyridonis, Gronli, Hansen and Ghinea, 2012; Wake, Sano, Oya, Sumitani, Kumagaya and Kuniyoshi, 2015), few used high-cost professional immersive VR solutions (9/29) (Carrougher et al., 2009; Dahlquist, Weiss, Clendaniel, Law, Ackerman, McKenna, 2009; Dahlquist, Herbert, Weiss and Jimeno, 2010; Dahlquist, et al., 2010; Rutter, Dahlquist and Weiss, 2009; Sil, et al., 2014; Gordon, Merchant, Zanbaka, Hodges and Goolkasian, 2011; Markus, et al., 2009; Wender, Hoffman, Hunner, Seibel, Patterson and Sharar, 2009) and the rest of the studies did not specify the type of HMD they used (7/29).

Some $(37.9 \%)$ of the interactivity and HMD devices were connected to a Desktop computer, Portable computer or a Console. To begin with, $13.8 \%$ of the studies used a Desktop computer to run the experiments (Czub and Piskorz, 2012; Dahlquist, Weiss, Clendaniel, Law, Ackerman and McKenna, 2009; Dahlquist et al., 2010; Crosbie, Lennon, McGoldrick, McNeill and McDonough, 2012). At the same rate, 13.8\% of the studies used a console, such as Playstation 2 (Dahlquist, Herbert, Weiss and Jimeno, 2010; Rutter, Dahlquist and Weiss, 2009), NintendoWii (Sil, et al., 2014) and Xbox 360 (Chen, Ponto, Sesto and Radwin, 2014). And finally, the $10.3 \%$ used portable computer (Maani, et al., 2011; Markus, et al., 2009; Morris, Louw and Crous, 2010). 


\subsubsection{Low Cost VR HMD}

Most studies (38.5\%) used Oculus Rift as an inexpensive VR solution (Chen, Ponto, Sesto and Radwin, 2014; Harvie, Broecker, Smith, Meulders, Madden and Moseley, 2015; Hoffman, et al., 2014; Sano, et al., 2015; Wake, et al., 2015).

Patients who suffer from chronic pain in specific body parts, such as neck, are usually dealing with kinesiophobia, the fear of movement. Oculus Rift was used, in order to influence the perception of patient's neck movement during the physiotherapy, revealing positive results (Chen, Ponto, Sesto and Radwin, 2014; Harvie, Broecker, Smith, Meulders, Madden and Moseley, 2015).

Studies also looked into the treatment of Phantom Limb Pain (PLP) with Oculus Rift and showed promising results. Limb amputation in many cases leads to an intense pain at the missing body part. The patients experience a strong chronic pain at the missing part, as if the part of the body still exists. Often medical pharmacological analgesics are not able to alleviate phantom pain. Through our review, we found two studies (Sano, et al., 2015; Wake, et al., 2015) on PLP and VR neurorehabilitation. Both studies used Oculus Rift and the same VR with small differences. This system could be applied to a future pain management platform offering flexible neurorehabilitation regimens for patients with PLP (Sano, et al., 2015; Wake, et al., 2015). Finally, Hoffman, et al., (2014) used Oculus Rift, for burn care with positive results.

Several studies (31\%) in burn care and thermal stimuli's conducted using the eMagin z800 3DVisor (Czub and Piskorz, 2012; 2014; Kipping, Rodger, Miller and Kimble, 2012; Morris, Louw and Crous, 2010).

Unlike previous studies described so far, eMagin z800 3DVisor revealed negative and no significant differences. Based on Morris, Louw and Crous (2010) no significant differences between the VR and NonVR session occurs using eMagin z800 3DVisor. Czub and Piskorz (2012) study reported that the participants were feeling more pain when they were using VR.

However, these findings does not confess the usefulness of eMagin z800 3DVisor, since in contrary to prior eMagin z800 3DVisor, revealed positive findings supporting statistically significant reduction in pain 
scores during dressing removal, to those receiving VR distraction, compared to those receiving standard distraction (Kipping, Rodger, Miller and Kimble, 2012).

i-glasses $920 H R$ were used for alleviating pain in wheelchair users and during dental treatment (Aminabadi, Erfanparast, Sohrabi, Oskouei and Naghili, 2011; Spyridonis, et al., 2012). Both studies reported positive results. Children who received dental treatment with VR distraction, compared to those received dental treatment without VR distraction, reported less pain and anxiety during the VR intervention (Aminabadi, Erfanparast, Sohrabi, Oskouei and Naghili, 2011). In addition to that, and smartphone-based VR application (PainDroid), revealed pain reduction through its use for wheelchair patients (Spyridonis, et al., 2012).

Only one study (Bahat, Takasaki, Chen, Bet-Or and Treleaven, 2015) deployed a VR system that could potentially be used as a home-based rehabilitation tool. This study investigated the kinematic impairments in patients with chronic neck pain, using the Vuzix Wrap 1200V HMD. The results revealed that patients who used the VR HMD in a short-term period felt less pain than KT patients. However, the VR effect didn't last through the five-weeks training. In other words, in long-term period the KTVR group was not better than the KT.

Maani, et al. (2011) used what is possibly the cheapest VR HMD, Goggles Cardboard, which is made of cardboard, powered by a Google Android Smartphone for burn care wound cleaning process showing a reduction in pain perception. Even though, this study used the lowest cost of VR HMD devise, however, they manage to publish significantly positive results.

\subsubsection{High Cost HMD}

Most of the high-cost HMD studies (44.5\%) used 5DT: 800-26 (Dahlquist, Weiss, Clendaniel, Law, Ackerman, McKenna, 2009; Dahlquist, et al., 2010; Rutter, Dahlquist and Weiss, 2009; Sil, et al., 2014). All the studies contacted with healthy population in order to identify how the VR affect the perception of an induced pain and the tolerance against the cold stimuli. Mix results were found with two of the studies reporting non statistically significant differences between the VR and the Non-VR condition (Dahlquist et 
al., 2010; Dahlquist, Herbert, Weiss and Jimeno, 2010), and two of the studies reporting VR's positive effect on pain management (Rutter, Dahlquist and Weiss, 2009; Sil, et al., 2014).

VFX3D HMD also used with cold stimuli experiment (Dahlquist, Herbert, Weiss and Jimeno, 2010) and revealed mixed results as well. These findings suggest that VR can enhance the effects of distraction for some children. This result underlines the importance of understanding the participant's characteristics in order to identify the suitable VR solution for them. However, VFX3D HMD revealed negative results based on an electrical stimulation pain experiment (Gordon, Merchant, Zanbaka, Hodges and Goolkasian, 2011).

More expensive solutions such as Nvis nVisor MH60 and ProView VO35, dealt with burn care pain management (Carrougher et al., 2009; Markus, et al., 2009). These experiments results suggest a significant decrease on procedural pain (Carrougher et al., 2009) and an important increase on procedural time (Markus, et al., 2009).

The most expensive VR HMD used to examine pain tolerance based on heat stimuli. This study (Wender, Hoffman, Hunner, Seibel, Patterson and Sharar, 2009) used Kaiser SR-80 and SnowWorld VE, applied at a healthy population, inducing pain with a thermal stimulation. Overall, this study suggests that the level of interaction during the session with immersive VR technology affects the participant's pain tolerance (Wender, Hoffman, Hunner, Seibel, Patterson and Sharar, 2009).

To conclude with, although these HMD are high costs solution (Table 5), we choose to include them into the systematic review since they are portable solutions. These high-cost HMD are headset's which can connect with a wired to a laptop, unlike systems like CAVE which takes up the whole room. As a result these studies used high-cost HMD solutions for VR pain management, but can be easily translated into low cost HMD technologies.

\begin{tabular}{llll}
\hline VR technology & Cost & Company & Website \\
\hline Kaiser SR-80 & $\$ 35000$ & Tek Gear & $\begin{array}{l}\text { http://www.tekgear.com/proview- } \\
\text { sr80.html }\end{array}$ \\
\hline Nvis nVisor MH60 & $\$ 23900$ & NVIS & http://www.nvisinc.com \\
\hline ProView VO35 & $\$ 5500$ & Ultimate3DHeaven & http://www.ultimate3dheaven.com/ \\
\hline 5DT: $800-26$ & $\$ 3995$ & 5DT & http://www.5dt.com/?page_id=36
\end{tabular}




\begin{tabular}{llll}
\hline VFX3D & $\$ 1800$ & IISVR & http://www.stereo3d.com/vfx3d.htm \\
\hline
\end{tabular}

Table 5: High-cost VR technologies

To conclude with, the cost of the HMD does not affect the effectiveness of the VR system. Low-cost VR HMD (Table 1), are suitable health care solutions for pain management. Although only one study looked into the use of VR in home settings, we believe that other studies using low cost VR solutions can also be practically carried out at home. Further studies need to be contacted in home settings, in order to improved home based pain management and identify the effectiveness of this tool. We hypothesize that this will leads in the improvement of health care and pain management, since patients will be able to manage pain and improve their physical rehabilitation in a daily basis. Also, VR pain management will not only increase patients' ability of more frequent physical therapy, but also will decrease the clinician cost. As a result patients will carry out more therapeutic sessions on their own. This may improve patients' health but also provide clinicians with extra time since they do not have to participate in each therapeutic session.

\subsection{Interactivity devices}

In additional to the HMD devices, $65.5 \%$ of the studies used other interactive devices to help the user to interact with the VR. Such devices included Keyboard, Computer mouse, Track ball hand controller, Joystick, Microsoft Kinect, and CYBERGLOVE $I^{2}$.

The most common interactivity solution was the keyboard (used by two studies), which was used for burn care treatment (Carrougher et al., 2009; Schmitt, et al., 2011) and a computer mouse (used by five studies) which was used for burn care (Hoffman, et al., 2014; Maani, et al., 2011; Markus, et al., 2009; Schmitt, et al., 2011) and cold stimuli experiments (Czub and Piskorz, 2014).

Joystick, was also used at the same rate as computer mouse (used by five studies), for burn care (Kipping, Rodger, Miller and Kimble, 2012; Morris, Louw and Crous, 2010), cold stimuli's (Dahlquist, Weiss, Clendaniel, Law, Ackerman and McKenna, 2009; Dahlquist et al., 2010) and electrical stimulation

\footnotetext{
${ }^{2}$ Kinect - Windows app development. (n.d.). Retrieved June 22, 2016, from https://developer.microsoft.com/en-us/windows/kinect

CyberGlove II. (n.d.). Retrieved June 22, 2016, from http://www.cyberglovesystems.com/cyberglove-ii Unfortunately, the articles do not provide us with the version of Keyboard, Computer mouse, Track ball hand controller and Joystick. Thus, we are unable to provide URL citation.
} 
(Gordon, Merchant, Zanbaka, Hodges and Goolkasian, 2011) experiments. Joystick is an input device consisting of a stick that spin on a base and reports its direction to the HMD devise it is controlling. Two types of Joysticks were used in these experiments: i) for burn care and cold stimuli's experiments it was used a Wired Logitech Joystick, whereas ii) for the electrical stimulation experiment it was used Wireless Joystick.

Track ball hand controller is a pointing device consisting of a ball secured by a hole full of sensors to detect the rotation of the ball. Two of the total studies used Track ball hand controller to interact and navigate in the VR during cystoscopy (Walker, Kallingal, Musser, Folen, Stetz, and Clark, 2014) and heat stimuli (Wender, Hoffman, Hunner, Seibel, Patterson and Sharar, 2009).

A more advance option of interactivity was CYBERGLOVE II and Microsoft Kinect used at two and three studies respectively. Both interaction devices were used for Phantom Limb Pain (Sano, et al., 2015; Wake, et al., 2015) whereas Microsoft Kinect was also used for cold stimuli experiment (Czub and Piskorz, 2014). CYBERGLOVE II is a wireless glove that capture's the hand motion, whereas Microsoft Kinect capture's the whole body movement.

\subsection{Intervention Strategies}

Based on the type of pain and the recommended treatments, the reviewed studies differ considerably in the VE content and the strategies on which the content was developed and delivered. We identified two main strategies: i) Distraction Strategy and ii) Altered Visual Feedback Strategy.

\subsubsection{Distraction Strategy}

Patients with burn injuries are dealing with a painful physical therapeutic process. Although this process is a fundamental component of patient's rehabilitation, by improving the functional outcomes and minimized persistent disabilities, burn patients usually neglect to participate fully in physical therapies, due to the significant procedural pain (Ehde, Patterson and Fordyce, 1998; Patterson and Sharar, 2001). Many studies on burn care provides suitable VR solutions of procedural pain management through the physical therapy 
(Carrougher et al., 2009; Hoffman, et al., 2014; Kipping, Rodger, Miller and Kimble, 2012; Maani, et al., 2011; Schmitt, et al., 2011).

VR burn care studies employed distraction as a design to manage procedural pain. Typically, two types of distraction are used: a) Single Distraction, and b) Advance Distraction.

The single type of distraction is distracting the patient from the painful possess by asking the patient to play a game through a VR interactive environment. A particularly good example was given from Kipping, Rodger, Miller and Kimble (2012) where the patients played a software game based on the appropriate age limit, younger patients played Chicken Little $^{3}$, whereas older patients were immersed in the Need for Speed $^{2}$ environment. In this case the patients played a simple game, which allows them to distract their self from the painful burn care procedure.

On the other hand, there as several studies that goes beyond that line and add in the VE some extra useful ice-features based on the patients population (e.g., Icy 3D Canyon, SnowWorld) using the advance type of distraction. The patient interact with the VE (e.g., via thronging snowballs) and gain a cooling feeling, based on the ice-features of the environment (Carrougher et al. 2009; Hoffman, et al., 2014; Maani, et al. 2011; Markus, et al. 2009; Schmitt, et al. 2011). As a result VR with Snow-VE creates an illusion of "cooling" effect by looking at the snowy environment. This VE provides the user with a complimentary useful feature on distraction strategy, as it is creating a "virtual cooling sensation" (Table 6).

Advance distraction strategy with ice-features incorporated in the VE, revealed a significant procedural pain reduction. Functional magnetic resonance imaging (fMRI) presented a great reduction in participants' pain-related brain activity, while they were using SnowWorld game during a thermal experiment (Hoffman, et, al., 2004; Hoffman, et, al., 2007).

Even SnowWorld is a well known VE for burn care, was also used as a possible solution of procedural pain management during Cystoscopy (Walker, Kallingal, Musser, Folen, Stetz, and Clark, 2014). Cystoscopy is a common ambulatory procedure performed in Urology and can be associated with moderate pain. Forty-

\footnotetext{
${ }^{3}$ The article does not provide us with the URL. Several versions of this game exist online.
} 
five male patients, aged 18 to70 participated in the experiment. Twenty-two patients had their Cystoscopy with a VR distraction, whereas the 23 controlled group participants had a normal Cystoscopy. No significant differences between the two groups were found. Based on the findings of this experiment, we can conclude that SnowWorld and VR distraction, with ice-features did not benefit male pain during Cystoscopy. VR is a useful tool on pain management. However, in order to be effective the VE content may consider the kind of pain and the requirement treatment.

On the other hand, although, there is a growing evidence supporting VR's efficiency in burn care and thermal stimuli for pain management based on distraction and cold VE, little has been written about the use of VR for treating patients with chronic pain and even less for consumer VR solutions oriented to chronic pain management.

Chronic pain could be any type of pain lasting more than 12 weeks and persists for months or in many cases for years. As a result of the complexity of this continues painful process, chronic pain is under investigation with less evidence on pain management.

It has been found that VR, via distraction could also reduce significantly painful symptoms from patients with chronic pain. Specifically, the representation of natural areas with the enhancement of relaxing music seems to decrease significantly pain (Wiederhold, Gao, Sulea and Wiederhold, 2014).

As stated above, we found a study (Bahat, Takasaki, Chen, Bet-Or and Treleaven, 2015) examining a solution that could be used as a home-based pain management and rehabilitation tool. This study (Bahat, Takasaki, Chen, Bet-Or and Treleaven, 2015) investigated the kinematic impairments in patients with chronic neck pain. The sample of this study was 32 adult patients with chronic neck pain (disability index NDI $>10 \%$ ). Participants were divided randomly into two groups: Kinematic (KT) and VR Kinematic (KTVR). Both groups completed four to six sessions, into a five-week period. The training sessions were consistent for both groups, which included head movements (fine, active and quick) and stability tasks, with 30 minutes overall. The KT group was doing the activities with a head mounted laser pointer and a poster, whereas the KTVR group was using HMD interacting with a VE. The VE consisted of a virtual pilot flying a red airplane controlled by the patient's head motion. The results reveal that patients who used the 
VR HMD in a short-term period felt less pain than KT patients. However, the VR effect didn't last through the five-weeks training. In other words, in long-term period the KTVR group was not better than the KT.

\begin{tabular}{|c|c|c|c|c|}
\hline Study & Participants & Interventions & Virtual Environment & Strategy \\
\hline Carrougher et al. (2009) & $\begin{array}{l}39 \text { Inpatients, } \\
\text { Aged: } 21-57\end{array}$ & VR / Non-VR & $\begin{array}{l}\text { Icy canyon in a river, a } \\
\text { waterfall and snowflakes }\end{array}$ & Advance Distraction \\
\hline Hoffman, et al. (2014) & $\begin{array}{l}\text { 1 Patient, } \\
\text { Aged: } 11\end{array}$ & VR / Non-VR & SnowWorld & Advance Distraction \\
\hline $\begin{array}{l}\text { Kipping, Rodger, Miller and } \\
\text { Kimble (2012) }\end{array}$ & $\begin{array}{l}41 \text { Patients, } \\
\text { Aged: } 11-17\end{array}$ & VR / Non-VR & $\begin{array}{l}\text { Chicken Little } \\
\text { Need for Speed }\end{array}$ & Single Distraction \\
\hline Maani, et al. (2011) & $\begin{array}{l}12 \text { Patients, } \\
\text { Aged: } 18+\end{array}$ & VR / Non-VR & SnowWorld & Advance Distraction \\
\hline Markus, et al. (2009) & $\begin{array}{l}12 \text { Patients, } \\
\text { Aged: } 18+\end{array}$ & - & SnowWorld & Advance Distraction \\
\hline $\begin{array}{l}\text { Morris, Louw and Crous } \\
(2010)\end{array}$ & $\begin{array}{l}11 \text { Patients, } \\
\text { Aged: } 23-54\end{array}$ & VR / Non-VR & Not specified & Not specified \\
\hline Schmitt, et al. (2011) & $\begin{array}{l}54 \text { Patients, } \\
\text { Aged: } 19+\end{array}$ & VR / Non-VR & SnowWorld & Advance Distraction \\
\hline \multicolumn{5}{|c|}{ Chronic Neck Pain } \\
\hline $\begin{array}{l}\text { Bahat, Takasaki, Chen, Bet- } \\
\text { Or and Treleaven (2015) }\end{array}$ & $\begin{array}{l}32 \text { Patients } \\
\text { Aged: } 18+\end{array}$ & VR / Non-VR & Pilot flying an airplane & Single Distraction \\
\hline \multicolumn{5}{|c|}{ Chronic Phantom Limb Pain (PLP) } \\
\hline Sano, et al. (2015) & 6 Patients & - & Reaching task & Single Distraction \\
\hline Wake, et al. (2015) & 5 Patients & - & Reaching task & Single Distraction \\
\hline \multicolumn{5}{|c|}{ Non- Specified } \\
\hline $\begin{array}{l}\text { Wiederhold, Gao, Sulea and } \\
\text { Wiederhold (2014) }\end{array}$ & $\begin{array}{l}40 \text { Patients, } \\
\text { Aged: } 22-68\end{array}$ & - & $\begin{array}{l}\text { Relaxing scenes of } \\
\text { natural areas }\end{array}$ & Single Distraction \\
\hline
\end{tabular}

Table 6: Characteristics of VR distraction strategy

\subsubsection{Altered Visual Feedback Strategy (AVFS) in Chronic Pain}

Kinesiophobia is the tendency to develop a fear of movement and is usually occurs to patients with chronic pain and leads in reduction in physical activity. Kinesiophobia has been detected to patients with chronic back and neck pain. In order to eliminate kinesiophobia and improve physical movement and rehabilitation, several VRs which alter the visual feedback of the patient in order to change motor behavior developed (Bolte, de Lussanet and Lappe, 2014; Chen, Ponto, Sesto and Radwin, 2014; Harvie, Broecker, Smith, Meulders, Madden and Moseley, 2015).

To illustrate a bit more, a promising VE using altered visual feedback strategy was a virtual basketball arena (Bolte, de Lussanet and Lappe, 2014). The participants were located in the centre of the virtual arena and performed a virtual basketball catching task based on their body rotation. The participant's feet were stabled on the ground. Small manipulation applied on the visual feedback to alter the way neck, back and 
hip contribute to the catching rotation. The results highlighted that VR and altered visual feedback strategy may increase back movement amplitudes in patients with chronic back pain.

Based on the same thinking pattern and with the aim to deal with chronic neck pain and kinesiophobia, a VE designed to provide the patient with an altered perception of his/her neck's motion (Chen, Ponto, Sesto and Radwin, 2014). The patient performs a target-aiming task, with neck movement. The goal was to align with the neck movement a depicted butterfly with a depicted net. The results of this study supports that altered visual feedback influenced patients movement, and as a consequence eliminates kinesiophobia.

Positive findings on altered visual feedback strategy were also reported by Harvie, et al. in 2015. In this experiment, altered visual cues used to examine movement pain. In detail, patients with chronic neck pain asked to rotate their heads. However, the visual feedback of the rotation overstated or understated the real rotation at $20 \%$ more or less of the real one. The results revealed that altered visual feedback may increase or decrease the pain perception based on the visual proprioceptive feedback (Table 7).

\begin{tabular}{|c|c|c|c|c|c|}
\hline \multicolumn{6}{|c|}{$\begin{array}{l}\text { Chronic Neck Pain } \\
\end{array}$} \\
\hline $\begin{array}{l}\text { Bahat, Takasaki, Chen, } \\
\text { Bet-Or and Treleaven } \\
(2015)\end{array}$ & $\begin{array}{l}32 \text { Patients } \\
\text { Aged: } 18+\end{array}$ & VR / Non-VR & Pilot flying an airplane & Distraction & $\begin{array}{l}\text { Positive: } \\
\text { Not lasting }\end{array}$ \\
\hline \multicolumn{6}{|c|}{$\begin{array}{c}\text { Chronic Phantom Limb Pain (PLP) } \\
\end{array}$} \\
\hline Sano, et al. (2015) & 6 Patients & - & Reaching task & Distraction & Positive \\
\hline Wake, et al. (2015) & 5 Patients & - & Reaching task & Distraction & Positive \\
\hline \multicolumn{6}{|c|}{ Non- Specified } \\
\hline $\begin{array}{l}\text { Wiederhold, Gao, Sulea } \\
\text { and Wiederhold (2014) }\end{array}$ & $\begin{array}{l}\text { 40 Patients, } \\
\text { Aged: } 22-68\end{array}$ & - & $\begin{array}{l}\text { Relaxing scenes of } \\
\text { natural areas }\end{array}$ & Distraction & Positive \\
\hline
\end{tabular}

Table 7: Characteristics of AVFS

\section{Discussion and Conclusion}

The finding of this systematic literature review indicates that VR could be a useful tool on pain management. However, the effectiveness of VR depends on the design strategies and the VR content based on the type of pain.

We considered the move from high-cost VR hardware to low-cost and portable ones for practical clinical use. The development of VR technologies in recent years have resulted in more accessible and less expensive solutions, which could still provide positive results. Based on our review we found a study (Maani, et al., 2011) which used what is possibly the cheapest VR HMD, Goggles Cardboard, which is 
made of cardboard, and the starting price is $\$ 14.95$. Even though, this study used an inexpensive VR HMD devise, however, it reveals positive results on pain management. Consequently, it is now conceivable to use VR technologies more widely in clinical contexts complementing traditional therapy and medical treatment, such as pharmacological oriented methods.

The low cost solutions which were suggested are often portable, meaning that the VR HMD can be plugged either into a laptop computer or a smartphone, as opposed to the need to instrument various sensor devices in a whole room such as the CAVE VR system. In addition to the hardware, several portable interactivity devices, such us Track ball hand controller, Joystick, Microsoft Kinect, and CYBERGLOVE, have been developed and can be adapted to VR HMD. This can result in the development of a holistic portable, accessible and usable system for pain management.

Furthermore, 3D animation modelling packages are now becoming very powerful for rapid creation of VE contexts at low cost. However, it stills require human resources to create the VE content. We believe there is a need for more accessible content creation tools which allows non-technical users to create clinically useful contents. These tools may include 360 video camera and 3D scanners.

Apart from 3D content creation tools, there are now easy-to-use Software Development Kits (SDK) to incorporate the content into integrated VR software providing interactive and immersive experience to users. Instead of time-consuming coding, visual programming (for instance using Blueprint in UDK engine $^{4}$ ) provides the developer with faster solutions. It is conceivable that in the future, non-technical users will be able to create VR software using intuitive SDKs with some training. Moreover, low-cost and accessible wearable sensing devices, which can easily connect to VR HMD, such as Microsoft Band ${ }^{5}$, have been developed which may substitute the existing high-cost sensing technologies. This will allow us to monitor patient's physiological signals while undergoing VR training.

\footnotetext{
${ }^{4}$ Blueprints Visual Scripting. (n.d.). Retrieved June 22, 2016, from https://docs.unrealengine.com/latest/INT/Engine/Blueprints/

${ }^{5}$ Microsoft Store - Xbox, Surface 3 Tablet, PC, Office, Windows Phone. (n.d.). Retrieved June 22, 2016, from http://www.microsoftstore.com/
} 
Based on the type of pain and the recommended treatments, VE content and the design strategies on which the content was developed and delivered, differ considerably. We identified two main strategies on VR pain management: i) Distraction and ii) Altered Visual Feedback Strategy. Both strategies have their merits.

Distraction is an effective strategy which allows the patient to concentrate on the virtual experience, thus distracting him/herself form perceiving nociceptive signals, and pain. This is by far the most commonly used strategy in pain management in the literature. Altered Visual Feedback Strategy triggers the patient's visual feedback and influence the perception of pain. The efficiency of each strategy depends on several factors, such as the type of pain, the type of the existing physical rehabilitation process and the participant's demographics (e.g., age).

Even though there is growing evidence that VR is a useful tool on pain management, there are mostly short-term studies. We found only one study (Bahat, Takasaki, Chen, Bet-Or and Treleaven, 2015) that compared the VR effect in short and long-term periods. This study indicates that although patients who used the VR HMD in a short-term period resulted in positive outcome, in long run, VR is not better than standard medication.

Further studies need to be conducted to explore whether VR could provide a sustainable long-lasting benefit in pain management. In addition, further studies need to be conducted in order to identify under what circumstances VR may provide a suitable solution on pain management. Based on these principles we will be able to identify the suitable strategy for each condition.

Finaly, there is a paucity of high quality data with high quality research methodology to review the role of VR in pain management. Of all the studies we reviewed, only one looked into the use of VR treatment at patient's home. Given the continuous advancement in usability of VR technologies and accompanying interactive devices, it is conceivable to foresee a future where VR rehabilitation can easily carried out at home with minimal clinical supervision. This will lead in the improvement of health care and pain management, since patients will be able to personally manage pain and improve their physical rehabilitation in their daily life or in their real-life context. 


\section{Bibliography}

Aminabadi, N. A., Erfanparast, L., Sohrabi, A., Oskouei, S. G., and Naghili, A. (2011). The Impact of Virtual Reality Distraction on Pain and Anxiety during Dental Treatment in 4-6 Year-Old Children: a Randomized Controlled Clinical Trial. Journal of Dental Research, Dental Clinics, Dental Prospects, 6(4), 117-124.

Arntz A., and Claassens L. (2004). The meaning of pain influences its experienced intensity. Pain, 109, $20-25$.

Bahat, H. S., Takasaki, H., Chen, X., Bet-Or, Y., and Treleaven, J. (2015). Cervical kinematic training with and without interactive VR training for chronic neck pain--a randomized clinical trial. Manual Therapy, 20(1), 68-78.

Bargas-Avila, J. A., and Hornbæk, K. (2011, May). Old wine in new bottles or novel challenges: a critical analysis of empirical studies of user experience. In Proceedings of the SIGCHI Conference on Human Factors in Computing Systems, 2689-2698. ACM.

Bolte, B., de Lussanet, M., and Lappe, M. (2014). Virtual reality system for the enhancement of mobility in patients with chronic back pain. Proc. 10th Intl Conf. Disability, Virtual Reality and Associated Technologies.

Carrougher, G. J., Hoffman, H. G., Nakamura, D., Lezotte, D., Soltani, M., Leahy, L., and Patterson, D. R. (2009). The effect of virtual reality on pain and range of motion in adults with burn injuries. Journal of Burn Care and Research: Official Publication of the American Burn Association, 30(5), 785-791.

Chen, K. B., Ponto, K., Sesto, M. E., and Radwin, R. G. (2014, September). Influence of altered visual feedback on neck movement for a virtual reality rehabilitative system. In Proceedings of the Human Factors and Ergonomics Society Annual Meeting, 58(1), 693-697. SAGE Publications. 
Crosbie, J. H., Lennon, S., McGoldrick, M. C., McNeill, M. D. J., and McDonough, S. M. (2012). Virtual reality in the rehabilitation of the arm after hemiplegic stroke: a randomized controlled pilot study. Clinical Rehabilitation, 26(9), 798-806.

Czub, M., and Piskorz, J. (2012). Effectiveness of Different Virtual Reality Environ-ments on Thermal Pain Distraction. Polish Journal of Applied Psychology, 10(2), 7-19.

Czub, M., and Piskorz, J. (2014). How Body Movement Influences Virtual Reality Analgesia? In Interactive Technologies and Games (iTAG), 2014 International Conference, 13-19. IEEE.

Dahlquist, L. M., Herbert, L. J., Weiss, K. E., and Jimeno, M. (2010). Virtual-reality distraction and coldpressor pain tolerance: does avatar point of view matter? Cyberpsychology, Behavior and Social Networking, 13(5), 587-591.

Dahlquist, L. M., Weiss, K. E., Clendaniel, L. D., Law, E. F., Ackerman, C. S., and McKenna, K. D. (2009). Effects of videogame distraction using a virtual reality type head-mounted display helmet on cold pressor pain in children. Journal of Pediatric Psychology, 34(5), 574-584.

Dahlquist, L. M., Weiss, K. E., Law, E. F., Sil, S., Herbert, L. J., Horn, S. B., and Ackerman, C. S. (2010). Effects of videogame distraction and a virtual reality type head-mounted display helmet on cold pressor pain in young elementary school-aged children. Journal of Pediatric Psychology, 35(6), 617625.

Deeks, J. J., Higgins, J., and Altman, D. G. (2008). Analysing data and undertaking meta-analyses. Cochrane handbook for systematic reviews of interventions: Cochrane book series, 243-296.

Ehde, D. M., Patterson, D. R., and Fordyce, W. E. (1998). The quota system in burn rehabilitation. Journal of Burn Care and Research, 19(5), 436-440. 
Gordon, N. S., Merchant, J., Zanbaka, C., Hodges, L. F., and Goolkasian, P. (2011). Interactive gaming reduces experimental pain with or without a head mounted display. Computers in Human Behavior, 27(6), 2123-2128.

Harvie, D. S., Broecker, M., Smith, R. T., Meulders, A., Madden, V. J., and Moseley, G. L. (2015). Bogus visual feedback alters onset of movement-evoked pain in people with neck pain. Psychological Science, 26(4), 385-392.

Hoffman, H. G., Meyer, W. J., 3rd, Ramirez, M., Roberts, L., Seibel, E. J., Atzori, B., and Patterson, D. R. (2014). Feasibility of articulated arm mounted Oculus Rift Virtual Reality goggles for adjunctive pain control during occupational therapy in pediatric burn patients. Cyberpsychology, Behavior and Social Networking, 17(6), 397-401.

Hoffman, H. G., Richards, T. L., Coda, B., Bills, A. R., Blough, D., Richards, A. L., and Sharar, S. R. (2004). Modulation of thermal pain-related brain activity with virtual reality: evidence from fMRI. Neuroreport, 15(8), 1245-1248.

Hoffman, H. G., Richards, T. L., Van Oostrom, T., Coda, B. A., Jensen, M. P., Blough, D. K., and Sharar, S. R. (2007). The analgesic effects of opioids and immersive virtual reality distraction: evidence from subjective and functional brain imaging assessments. Anesthesia and analgesia, 105(6), 1776-1783.

Hoffman, H. G., Seibel, E. J., Richards, T. L., Furness, T. A., Patterson, D. R., and Sharar, S. R. (2006). Virtual reality helmet display quality influences the magnitude of virtual reality analgesia. The Journal of Pain, 7(11), 843-850.

Hyattsville, M. D., and National Center for Health Statistics, (2007). Health, United States, 2006 with Chartbook on Trends in the Health of Americans.

Khan, K. S., Ter Riet, G., Glanville, J., Sowden, A. J., \& Kleijnen, J. (2001). Undertaking systematic reviews of research on effectiveness: CRD's guidance for carrying out or commissioning reviews (No. 4 (2n). NHS Centre for Reviews and Dissemination. 
Kipping, B., Rodger, S., Miller, K., and Kimble, R. M. (2012). Virtual reality for acute pain reduction in adolescents undergoing burn wound care: a prospective randomized controlled trial. Burns: Journal of the International Society for Burn Injuries,38(5), 650-657.

Li, A., Montaño, Z., Chen, V. J., and Gold, J. I. (2011). Virtual reality and pain management: current trends and future directions. Pain management, 1(2), 147-157.

Ma, M., and Zheng, H. (2011). Virtual reality and serious games in healthcare. In Advanced Computational Intelligence Paradigms in Healthcare 6. Virtual Reality in Psychotherapy, Rehabilitation, and Assessment, 169-192. Springer Berlin Heidelberg.

Maani, C. V., Hoffman, H. G., Morrow, M., Maiers, A., Gaylord, K., McGhee, L. L., and DeSocio, P. A. (2011). Virtual reality pain control during burn wound debridement of combat-related burn injuries using robot-like arm mounted VR goggles. The Journal of Trauma, 71(1), 125-130.

Markus, L. A., Willems, K. E., Maruna, C. C., Schmitz, C. L., Pellino, T. A., Wish, J. R., and Schurr, M. J. (2009). Virtual reality: feasibility of implementation in a regional burn center. Burns: Journal of the International Society for Burn Injuries, 35(7), 967-969.

Matsangidou, M., Ang, C. S., Mauger, A. R., Otkhmezuri, B., and Tabbaa, L. (2017, September). How Real is Unreal? Virtual Reality and the Impact of Visual Imagery on the Experience of ExerciseInduced Pain. In Human-Computer Interaction - INTERACT 2017. Springer International Publishing.

Merskey, H., and Bogduk, N. (1994). Classification of chronic pain. Seattle, WA: IASP Press.

Morris, L. D., Louw, Q. A., and Crous, L. C. (2010). Feasibility and potential effect of a low-cost virtual reality system on reducing pain and anxiety in adult burn injury patients during physiotherapy in a developing country. Burns: Journal of the International Society for Burn Injuries, 36(5), 659-664.

Moseley, G. L. (2003). A pain neuromatrix approach to patients with chronic pain. Manual therapy, 8(3), 130-140. 
Patterson, D., and Sharar, S. (2001). Burn pain. Bonica's management of pain, 3, 780-787.

Price, D. D. (1999). Psychological mechanisms of pain and analgesia. Seattle, WA: IASP Press.

Riva, G. (2005). Virtual reality in psychotherapy: review. Cyberpsychology and behavior, 8(3), 220-230.

Rothbaum, B. O., Hodges, L., and Kooper, R. (1997). Virtual reality exposure therapy. Journal of Psychotherapy Practice and Research.

Rutter, C. E., Dahlquist, L. M., and Weiss, K. E. (2009). Sustained efficacy of virtual reality distraction. The Journal of Pain: Official Journal of the American Pain Society, 10(4), 391-397.

Sano, Y., Ichinose, A., Wake, N., Osumi, M., Sumitani, M., Kumagaya, S.-I., and Kuniyoshi, Y. (2015). Reliability of phantom pain relief in neurorehabilitation using a multimodal virtual reality system. Conference Proceedings: Annual International Conference of the IEEE Engineering in Medicine and Biology Society. IEEE Engineering in Medicine and Biology Society. Conference, 2015, $2482-2485$.

Schmitt, Y. S., Hoffman, H. G., Blough, D. K., Patterson, D. R., Jensen, M. P., Soltani, M., and Sharar, S. R. (2011). A randomized, controlled trial of immersive virtual reality analgesia, during physical therapy for pediatric burns. Burns: Journal of the International Society for Burn Injuries, 37(1), 6168.

Schneider, S. M., Kisby, C. K., and Flint, E. P. (2011). Effect of virtual reality on time perception in patients receiving chemotherapy. Supportive Care in Cancer: Official Journal of the Multinational Association of Supportive Care in Cancer,19(4), 555-564.

Sil, S., Dahlquist, L. M., Thompson, C., Hahn, A., Herbert, L., Wohlheiter, K., and Horn, S. (2014). The effects of coping style on virtual reality enhanced videogame distraction in children undergoing cold pressor pain. Journal of Behavioral Medicine, 37(1), 156-165.

Spyridonis, F., Gronli, T.-M., Hansen, J., and Ghinea, G. (2012). Evaluating the usability of a virtual reality-based Android application in managing the pain experience of wheelchair users. Conference 
Proceedings: Annual International Conference of the IEEE Engineering in Medicine and Biology Society. IEEE Engineering in Medicine and Biology Society. Conference, 2460-2463.

Wake, N., Sano, Y., Oya, R., Sumitani, M., i. Kumagaya, S., and Kuniyoshi, Y. (2015). Multimodal virtual reality platform for the rehabilitation of phantom limb pain. In Neural Engineering (NER), 2015 7th International IEEE/EMBS Conference, 787-790.

Walker, M. R., Kallingal, G. J. S., Musser, J. E., Folen, R., Stetz, M. C., and Clark, J. Y. (2014). Treatment efficacy of virtual reality distraction in the reduction of pain and anxiety during cystoscopy. Military Medicine, 179(8), 891-896.

Wender, R., Hoffman, H. G., Hunner, H. H., Seibel, E. J., Patterson, D. R., and Sharar, S. R. (2009). Interactivity Influences the Magnitude of Virtual Reality Analgesia. Journal of Cyber Therapy and Rehabilitation, 2(1), 27-33.

Wiederhold, B. K., Gao, K., Sulea, C., and Wiederhold, M. D. (2014). Virtual reality as a distraction technique in chronic pain patients. Cyberpsychology, Behavior and Social Networking, 17(6), 346352.

Wiederhold, M. D., Gao, K., and Wiederhold, B. K. (2014). Clinical use of virtual reality distraction system to reduce anxiety and pain in dental procedures. Cyberpsychology, Behavior and Social Networking, 17(6), 359-365. 